\title{
Oral Manifestations of Celiac Disease
}

\author{
Luca Pastore, DDS,* Antonio Carroccio, MD, $\dagger$ Domenico Compilato, DDS, $\$$ \\ Vera Panzarella, DDS, + Rosario Serpico, MD, $\S$ and Lorenzo Lo Muzio, MD*
}

\begin{abstract}
Introduction: Contrary to early beliefs, celiac disease (CD) is relatively common; however, it still remains underdiagnosed since most cases are atypical, with few or no gastrointestinal symptoms and predominance of extraintestinal manifestations. As a consequence, the diagnosis of the disorder often requires a multidisciplinary approach. Also some oral ailments have been described in celiac patients. In this study, we review the papers that have reported oral manifestations in subjects with CD.
\end{abstract}

Methods: A comprehensive literature search was conducted in Medline and Embase databases using appropriate key words. Additional papers were selected by cross-referencing from the retrieved articles.

Results: Dental enamel defects are the oral lesions most closely related to $\mathrm{CD}$. There are conflicting data on the association between $\mathrm{CD}$ and recurrent aphthous stomatitis. A correlation of $\mathrm{CD}$ with atrophic glossitis has been reported, although robust evidence in support of it is lacking. Patients with CD have caries indexes seemingly lower than healthy individuals, but they may experience delay in tooth eruption. Occurrence of other oral mucosal lesions in $\mathrm{CD}$ subjects is likely occasional.

Conclusions: Patients with systematic dental enamel defects should be screened for $\mathrm{CD}$ even in the absence of gastrointestinal symptoms. CD screening tests for patients with oral aphthae or idiopathic atrophic glossitis should be selectively considered during a medical evaluation that focuses on all aspects of the patient's status.

Key Words: atrophic glossitis, case-finding, celiac disease, dental enamel defects, recurrent aphthous stomatitis

( J Clin Gastroenterol 2008;42:224-232)

C eliac disease $(\mathrm{CD})$ is a lifelong immune-mediated disorder triggered by the ingestion of wheat gluten and related proteins of rye and barley in genetically

From the *Department of Surgical Sciences, University of Foggia; Departments of $\dagger$ Internal Medicine; †Oral Sciences, University of Palermo; and §Department of Oral Disciplines, Second University of Naples, Italy.

The authors declare no conflict of interest.

Supported in part by PRIN 2005 from Ministry of University and Research, Italy.

Reprints: Dr Luca Pastore, DDS, Dip. Scienze Chirurgiche, Università degli Studi di Foggia, c/o Ospedali Riuniti, viale Pinto, 71100 Foggia, Italy (e-mail: lpastore@yahoo.com).

Copyright (C) 2008 by Lippincott Williams \& Wilkins susceptible subjects, which results in small intestinal mucosal injury and nutrient malabsorption.

Until recently considered a rare condition, $\mathrm{CD}$ is now well-known to be relatively common; its estimated prevalence in the general population of North America and Western Europe appears to be close to $1 \%$, with a reasonable range of $0.71 \%$ to $1.25 \%{ }^{1}$ The dramatic advances made during the last decade in the understanding of $\mathrm{CD}$ have revealed the disease to have a heterogeneous, wide, and often unsuspected range of clinical presentations. In fact, today it is apparent that the "classic" clinical form (characterized by a malabsorption syndrome, ie, chronic diarrhea, abdominal pain and distention, weight loss) is less common, and most patients have atypical $\mathrm{CD}$, with few or no gastrointestinal symptoms and predominance of extraintestinal manifestations, such as short stature, iron-deficient anemia, abnormalities in liver function test. ${ }^{2} \mathrm{CD}$ patients are prone to develop long-term complications (eg, osteoporosis, infertility, autoimmune diseases, malignancies), ${ }^{3}$ and some studies report an increased all-cause mortality compared with the general population. ${ }^{4,5}$ Strict and lifelong adherence to a gluten-free diet (GFD) is the only treatment currently available, and usually results in remission. Compelling evidence suggests that GFD may prevent or reduce the risk of long-term complications. ${ }^{3}$

The wide range of the $\mathrm{CD}$ clinical manifestations should induce many different specialists to consider this disorder when a patient presents with those extraintestinal signs and symptoms that might be related to $\mathrm{CD} .{ }^{6} \mathrm{In}$ this regard, also some oral ailments have been reported as possible atypical aspects of $\mathrm{CD}$, mainly dental enamel defects (DEDs) and recurrent aphthous stomatitis (RAS). The aim of our study was to review the papers that have described oral manifestations in subjects with CD.

\section{METHODS}

A comprehensive literature search was conducted in Medline and Embase databases using the key words "celiac disease," "coeliac disease," and "dermatitis herpetiformis" combined separately with the terms "oral cavity," "oral lesions," "dental enamel defects," "recurrent aphthous stomatitis," "oral ulcers," "glossitis," "Plummer-Vinson syndrome," "oral lichen planus," "dental caries," "dental decay," and "dental age." Potentially relevant papers were selected on the basis of title and abstract, and the full manuscripts were retrieved and reviewed. For papers that were neither in English nor 
Italian, only the abstract was reviewed; if no abstract was available, the article was discarded. Additional papers were selected by a manual search of the reference lists of the retrieved articles.

\section{AND ORAL HARD TISSUE LESIONS}

\section{DEDs}

During enamel matrix deposition and calcification, genetic and/or environmental factors can cause DEDs, which may be quantitative or qualitative. Disturbances in matrix secretion can cause enamel hypoplasia, which presents as deficiency of enamel quantity, whereas qualitative defects present as enamel opacity and are due to disruptions occurring during the calcification phase of enamel formation. ${ }^{7}$

An association between gastrointestinal diseases and developmental defects of dental enamel was described since early 1900s, when the term "dental atrophy" was used for dental malformations owing to disorders interfering with a normal nutrition. ${ }^{8}$ In 1955, pronounced DEDs were described in a 7-year-old girl with clinical features of $\mathrm{CD},{ }^{9}$ and in 1956,7 patients with $\mathrm{CD}$ were examined, 3 of whom exhibited DEDs of the permanent dentition. ${ }^{10}$ Thereafter, other cases of DEDs in subjects with CD were reported, ${ }^{10,11}$ and 8 out of 18 celiac children had DEDs of permanent teeth in a series reviewed in $1973 .{ }^{12}$

To the contrary, only 9 out of 252 patients with CD were described as having mild to severe enamel hypoplasia in a study realized in $1980 .{ }^{13}$ Besides, the first controlled study available in English literature which investigated the presence of DEDs in CD patients reported no significant difference between celiac subjects and healthy controls. ${ }^{14}$ However, in 1986 Aine $^{15}$ provided the strongest evidence that DEDs may be an extraintestinal manifestation of CD, reporting a $95.94 \%$ prevalence of DEDs of permanent teeth in 74 children with $C D$. In this study, the celiac-type DEDs were defined as "systematic," as they were symmetrically and chronologically distributed in all 4 sections, reflecting the period in which disruptions interfered with amelogenesis. The author proposed a grading system (from grade I to IV) to classify the severity of the CD-related enamel lesions, from simple opacities to severe structural defects (Table 1).

Almost all the subsequent controlled studies reported prevalence values of DEDs significantly higher in CD patients than in nonceliac individuals, and confirmed that the celiac-type enamel defects are systematic, as differences for unspecific and unsystematic defects were not significant (Table 2).

The reason for the presence of DEDs in celiac patients still remains not clear. Hypocalcemia due to malabsorption could be a possible cause, in agreement with the unifying hypothesis on mechanism of enamel hypoplasia development. ${ }^{37}$ However, no differences in mean serum calcium concentration were found between celiac children with and without dental lesions, ${ }^{27}$ and celiac-type DEDs were also detected in healthy first-
TABLE 1. Grading of the CD-related DEDs According to Aine ${ }^{15}$

\begin{tabular}{ll}
\hline Grade & \multicolumn{1}{c}{ DED } \\
\hline Grade I & $\begin{array}{l}\text { Defect in color of enamel } \\
\text { Single or multiple creams, yellow or brown opacities with } \\
\text { clearly defined or diffuse margins; a part or the entire } \\
\text { surface of enamel is without glaze } \\
\text { Slight structural defects } \\
\text { Enamel surface rough, filled with horizontal grooves or } \\
\text { shallow pits; light opacities and discoloration may be } \\
\text { found; a part or the entire surface of enamel is without } \\
\text { glaze } \\
\text { Evident structural defects } \\
\text { A part or the entire surface of enamel rough and filled } \\
\text { with deep horizontal grooves which vary in width or } \\
\text { have large vertical pits; large opacities of different } \\
\text { colors or strong discolouration may be in combination } \\
\text { Severe structural defects } \\
\text { The shape of the tooth changed: the tips of cusps are } \\
\text { sharp-pointed and/or the incisal edges are unevenly } \\
\text { thinned and rough; the thinning of the enamel material } \\
\text { is easily detectable and the margins of the lesions are } \\
\text { well defined; the lesion may be strongly discolored }\end{array}$ \\
& \\
&
\end{tabular}

degree relatives of celiac patients having normal smallbowel mucosal architecture. ${ }^{38}$ So, a gluten-induced, immune-mediated enamel damage should seem a more likely cause of DEDs in celiac patients. Consistently with this hypothesis, CD-associated dental changes were found significantly related to HLA antigen DR 3. ${ }^{22,27}$ Furthermore, a strong association between the same HLA allele and celiac-type DEDs were also demonstrated in healthy first-degree relatives of celiac patients. ${ }^{38}$ Hypocalcemia resulting from malabsorption could be nevertheless a contributing factor in inducing defective enamel formation. ${ }^{39}$

A few studies compared the prevalence of celiactype DEDs in deciduous and mixed/permanent dentition, and all of these reported that they are more prevalent in the mixed/permanent dentition. ${ }^{16,23,27}$ The overall prevalence of systematic CD-related DEDs in patients with mixed/permanent dentition ranges from $9.52 \%$ to $95.94 \%$ (with a mean value of $51.12 \%$ ), whereas that for CD patients with deciduous teeth is $5.88 \%$ to $13.33 \%$ (mean: $9.60 \%$ ). The higher prevalence for the permanent dentition could be explained by the fact that the development of crowns of permanent teeth occurs between the early months of life and the seventh year (ie, after the introduction of gluten), whereas the formation of deciduous teeth mainly occurs in utero. But the presence of DEDs also in deciduous teeth supports the hypothesis that immuno-genetical factors are more likely involved in development of CD-related dental defects rather than nutritional deficiencies, or at least these represent the main cause.

The distribution of different grades of DEDs (according to the classification of Aine) shows that grade I and II defects are on the whole most common (Table 3). It is unclear which factors affect the severity of enamel defects in CD patients. It was reported that the celiac-type 
TABLE 2. Prevalence of DEDs in Patients With CD

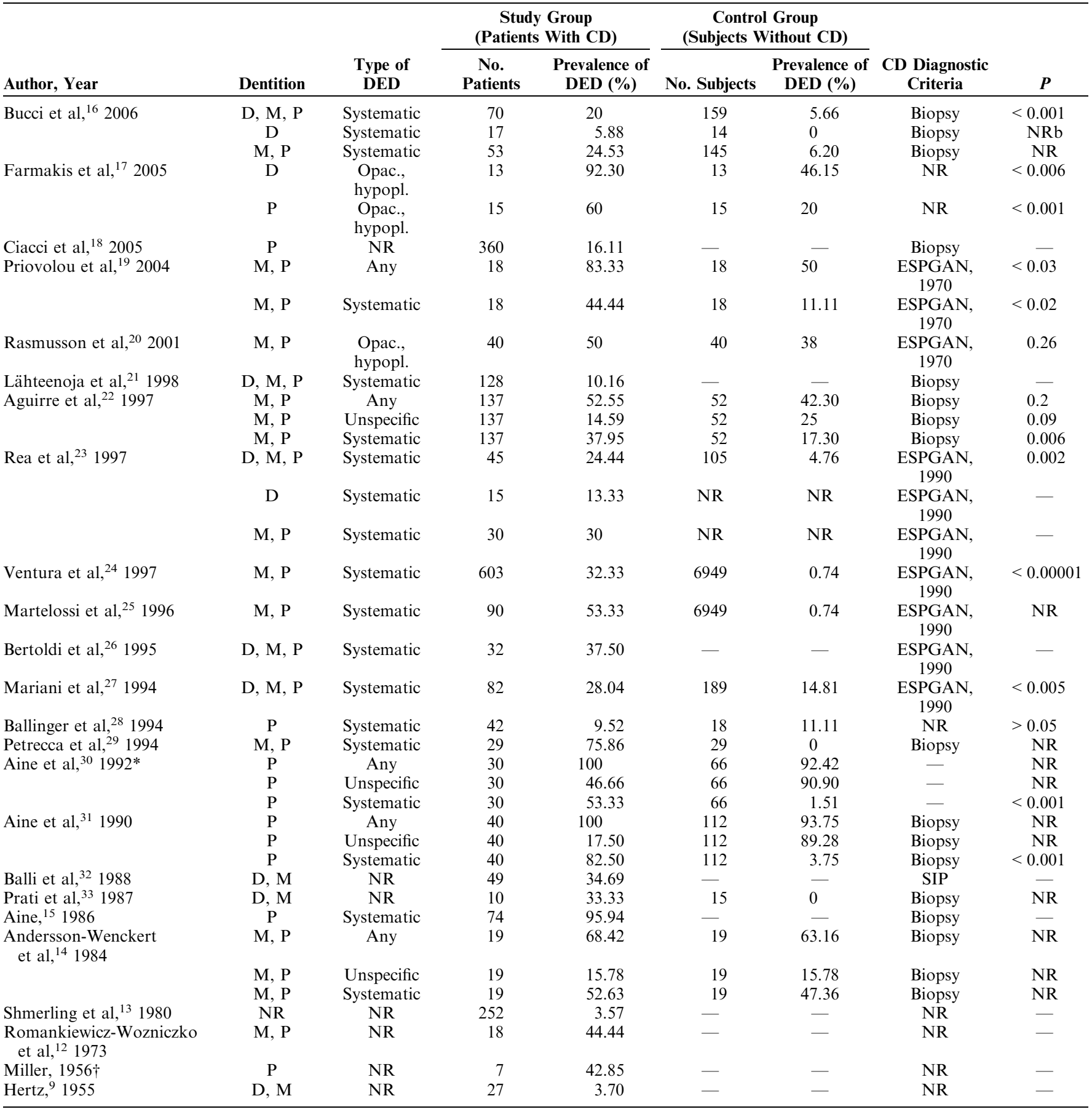

*This study was performed on patients with DH

$\dagger$ Data reported in Smith et al, ${ }^{10} 1979$.

D indicates deciduous; ESPGAN, European Society of Paediatric Gastroenterology and Nutrition (references of the diagnostic criteria: Meeuwisse, ${ }^{34}$ 1970; WalkerSmith et al, ${ }^{35}$ 1990); hypopl, hypoplasias; M, mixed; NR, not reported, Opac, opacities; P, permanent; SIP, Società Italiana di Pediatria (Italian Society of Pediatrics; reference of the diagnostic criteria: Italian Society of Pediatrics, ${ }^{36}$ 1978).

DEDs in adults are much less severe than in children, despite a similar prevalence. ${ }^{31}$ In fact, no grade IV and only 1 case of grade III defects were found out of 40 adult celiac subjects (with a mean age at diagnosis of $34 \mathrm{y}$ ), whereas nearly $30 \%$ of children with CD had grade III or IV DEDs. This considerable difference could indicate that the adult patients had had a clinically mild or atypical disease at childhood, which had led to a late diagnosis 
TABLE 3. Distribution of Grades of CD-related DEDs

\begin{tabular}{|c|c|c|c|c|c|c|}
\hline Author, Year & Dentition & $\begin{array}{c}\text { No. CD } \\
\text { Patients With } \\
\text { DEDs } \\
\end{array}$ & $\begin{array}{c}\text { No. CD Patients } \\
\text { With Grade I } \\
\text { DEDs (\%) }\end{array}$ & $\begin{array}{c}\text { No. CD Patients } \\
\text { With Grade II } \\
\text { DEDs (\%) }\end{array}$ & $\begin{array}{c}\text { No. CD Patients } \\
\text { With Grade III } \\
\text { DEDs (\%) }\end{array}$ & $\begin{array}{c}\text { No. CD Patients } \\
\text { With Grade IV } \\
\text { DEDs (\%) } \\
\end{array}$ \\
\hline Bucci et al, ${ }^{16} 2006$ & $\mathrm{D}, \mathrm{M}, \mathrm{P}$ & 14 & $7(50 \%)$ & $4(28.57 \%)$ & $2(14.28 \%)$ & $1(7.14 \%)$ \\
\hline Aguirre et al, ${ }^{22} 1997$ & $\mathrm{M}, \mathrm{P}$ & 52 & $32(61.54 \%)$ & $16(30.77 \%)$ & $3(5.77 \%)$ & $1(1.92 \%)$ \\
\hline Rea et al, $^{23} 1997$ & $\mathrm{D}, \mathrm{M}, \mathrm{P}$ & 11 & $5(45.45 \%)$ & $4(36.36 \%)$ & $2(18.18 \%)$ & $0(0 \%)$ \\
\hline Martelossi et al, ${ }^{25} 1996$ & $\mathrm{M}, \mathrm{P}$ & 48 & $8(16.66 \%)$ & $22(45.83 \%)$ & $14(29.17 \%)$ & $4(8.33 \%)$ \\
\hline Petrecca et al, ${ }^{29} 1994$ & $\mathrm{M}, \mathrm{P}$ & 22 & $10(45.45 \%)$ & $9(40.90 \%)$ & $2(9.09 \%)$ & $1(4.54 \%)$ \\
\hline Aine, ${ }^{15} 1986$ & $\mathrm{P}$ & 71 & $10(14.08 \%)$ & $39(54.93 \%)$ & $14(19.72 \%)$ & $8(11.27 \%)$ \\
\hline
\end{tabular}

*This study was performed on patients with $\mathrm{DH}$

$\mathrm{D}$ indicates deciduous; $\mathrm{M}$, mixed; $\mathrm{P}$, permanent.

and slight dental lesions. ${ }^{31}$ In support of this hypothesis, a correlation between the severity of CD clinical presentation and the grade of DEDs was also demonstrated. ${ }^{15}$ However, a higher prevalence of enamel lesions in patients with atypical or asymptomatic CD was found, ${ }^{16}$ and a study on patients affected by the CD-related dermatitis herpetiformis (DH) demonstrated no correlation between the degree of mucosal damage and the presence of DEDs. ${ }^{30}$

The hypothesis that late diagnosis and prolonged gluten exposure relate to the likelihood of DEDs was supported by a few studies, which demonstrated that mean age at diagnosis of $\mathrm{CD}$ is significantly higher in patients with dental defects, ${ }^{24,28}$ although others failed to do so. ${ }^{16,27}$ Furthermore, in a series of 360 adults with $C D$, no case of DEDs was described among patients with proved $\mathrm{CD}$ diagnosis in childhood and on a strict GFD since diagnosis, whereas DEDs were found in $18 \%$ of patients with early diagnosis but who were reexposed to gluten, and in $26 \%$ of adults with newly diagnosed CD. ${ }^{18}$

Concerning the location of the CD-related DEDs, incisors are the teeth most frequently affected, followed by molars, canines, and premolars. ${ }^{16,22}$ This distribution should seem related to the chronology of development of the permanent dentition, as incisors and first molars are the first teeth that undergo calcification; the lesser involvement of teeth that calcify at a later stage could be explained considering that their calcification starts when $\mathrm{CD}$ has been possibly already diagnosed, and gluten removed from diet. ${ }^{22}$ Instead, in nonceliac subjects dental defects seem to be equally distributed for all the teeth, ${ }^{16,22}$ with significant difference with respect to the involvement of incisors as compared with CD patients. ${ }^{22}$ In regard to the distribution of DEDs on the coronal surface, the incisal third resulted the most affected surface both in CD and control groups; however, involvement of the incisal two thirds or of the complete crown were also observed in celiac patients, whereas none of the control group showed this coronal involvement, and the difference resulted statistically significant. ${ }^{22}$

\section{Dental Caries}

Several studies investigated the prevalence of dental caries in celiac patients. Some of these reported no difference in caries prevalence between celiac individuals and control healthy subjects..$^{26,29,33,40}$ Rather surprisingly, others found caries indexes significantly lower in CD subjects than controls. ${ }^{14,17,19,22}$ No study reported higher dental caries prevalence among celiac patients. A possible explanation for these findings is that the need for a carefully controlled diet should make CD patients more diet-conscious, so that they maybe have a low cariogenic diet. ${ }^{14,17,22}$

\section{Dental Age}

Dental age was studied in 49 children with $\mathrm{CD}^{32}$ : delay in tooth eruption, estimated according to the dental standard of Schour and Massler, ${ }^{41}$ was noticed in $28.57 \%$ of patients. Similarly, the dental age was delayed in relation to calendar age in one third of 38 children with CD examined in a Polish study. ${ }^{42}$ Furthermore, we have recently observed delayed eruption in $26 \%$ of pediatric CD patients, as opposed to $7 \%$ of the controls (unpublished observations). These findings are likely related to the growth retardation, that is a typical sign of $\mathrm{CD}$.

\section{AND ORAL SOFT TISSUE LESIONS}

\section{RAS}

RAS is characterized by painful, recurrent, single or multiple ulcers of the oral mucosa, which are round or ovoid and have an erythematous halos and a yellow or gray floor. It is one of the most common mouth diseases, affecting $5 \%$ to $60 \%$ of the population depending on the group studied ${ }^{43}$; it has been estimated that $20 \%$ of the general population will suffer from RAS at some time in their lives. ${ }^{44}$ Approximately $80 \%$ of patients with RAS have minor aphthae, that are 2 to $8 \mathrm{~mm}$ in diameter and usually resolve spontaneously within 2 weeks. Major RAS is much less common, with ulcers that may exceed $1 \mathrm{~cm}$ in diameter and persist for several weeks. The least common type of RAS is termed "herpetiform" and is characterized 
by clusters of small ulcers (as many as 100 or more, 1 to $3 \mathrm{~mm}$ in diameter) that tend to coalesce producing large irregular ulcerations.

The term "recurrent aphthous stomatitis" should be reserved for recurrent ulcers occurring in subjects without systemic diseases, whereas ulcers that resemble RAS but found in systemic disorders should be termed "aphthouslike ulcers." ${ }^{45}$ However, these 2 expressions are often used indistinctly, and all the papers we reviewed discussed RAS as a possible CD-associated oral disease. So, herein we use the term RAS as well, even though aphthouslike ulcersshould be a more appropriate expression to describe recurrent oral ulcerations in celiac patients.

An association between oral ulcers, diarrhea, and weight loss has been described for more than 3 centuries, ${ }^{46}$ and the early studies that investigated the prevalence of $\mathrm{CD}$ in patients affected by RAS reported very high values (Table 4). Notably, Ferguson et $\mathrm{al}^{46}$ quoted a $24.24 \%$ prevalence of $C D$ in 33 patients with RAS, and asserted the importance of performing jejunal biopsy in subjects with recurrent aphthae. Subsequent studies $^{54-56}$ lessened this matter, albeit they reported CD prevalence values higher than those expected for the normal population, and thus supported the hypothesis of a correlation between CD and RAS. On the contrary, in 1986 only 1 of 100 patients with RAS had histologic evidence of $\mathrm{CD},{ }^{53}$ and no $\mathrm{CD}$-affected patient has been recently described among 87 subjects with RAS. ${ }^{49}$ However, in the only 2 controlled studies that have searched for $\mathrm{CD}$ in patients with $\mathrm{RAS},{ }^{47,48}$ histologic signs of $\mathrm{CD}$ have been demonstrated in nearly $5 \%$ of patients with RAS, whereas none of the biopsies obtained from controls revealed the disease.

The evidence of a correlation between the 2 conditions was less robust when we considered studies, which examined the prevalence of RAS in CD patients (Table 5). In fact, $9.66 \%{ }^{64}$ to $26.53 \%{ }^{32}$ of celiac subjects resulted with RAS in uncontrolled studies, a prevalence similar to that estimated for the general population.
Furthermore, all the controlled studies ${ }^{14,16,21,60}$ failed to demonstrate any statistically significant difference between CD and control groups, even though it is worth noting that prevalence values of RAS resulted constantly higher in celiac patients than controls.

A support for the hypothetical correlation between $\mathrm{CD}$ and RAS is provided by the observation that GFD may be effective in the management of RAS. In fact, several authors reported significant improvement, if not complete remission, of oral aphthae in most CD patients which had been placed on GFD, ${ }^{16,46,55,65}$ and reappearance of recurrences with the reintroduction of gluten. ${ }^{52,54,62,63}$ Furthermore, patients with RAS and no histologic evidence of CD showed a favorable response to GFD and a positive gluten challenge, suggesting the existence of a form of gluten-sensitive RAS. ${ }^{66}$ On the other hand, a double-blind controlled study examined the effect of GFD in patients with RAS and without CD; 4 of the 11 subjects on GFD reported benefit as regards the oral aphthae, but no significant statistical difference was observed as compared with control subjects which underwent GFD supplemented by gluten given blind. ${ }^{67}$

Concerning the severity of aphthae in CD subjects, most papers assert that celiac patients with RAS suffer from minor aphthae. ${ }^{53,55,57,62,63}$ However, cases of CD patients with major or herpetiform RAS were also reported. ${ }^{54}$

A possible explanation for the hypothetical correlation between CD and RAS is that oral aphthae in CD patients could be related to hematinic deficiencies (iron, folic acid, or vitamin $B_{12}$ ). In fact, about $20 \%$ of subjects with RAS may have a hematinic deficiency, ${ }^{43}$ and the serum levels of iron, folic acid, and vitamin $\mathrm{B}_{12}$ are usually low in patients with untreated CD. ${ }^{68}$ Consistently with this hypothesis, hemoglobin and serum folate levels were found significantly lower in patients affected by both RAS and CD than in nonceliac subjects with RAS. ${ }^{46,58}$ Moreover, all the 5 cases of $\mathrm{CD}$ diagnosed in a series of

TABLE 4. Prevalence of CD in Patients With RAS

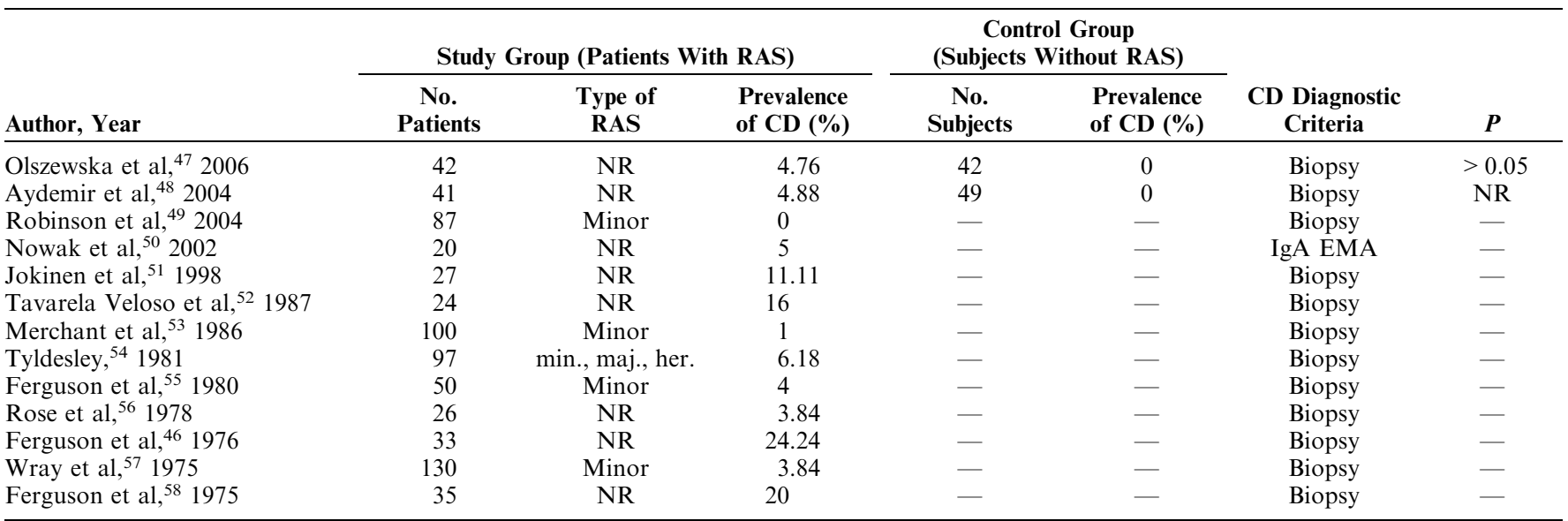

EMA indicates endomysium antibodies; her., herpetiform; min., minor; maj., major; NR, not reported. 
TABLE 5. Prevalence of RAS in Patients With CD

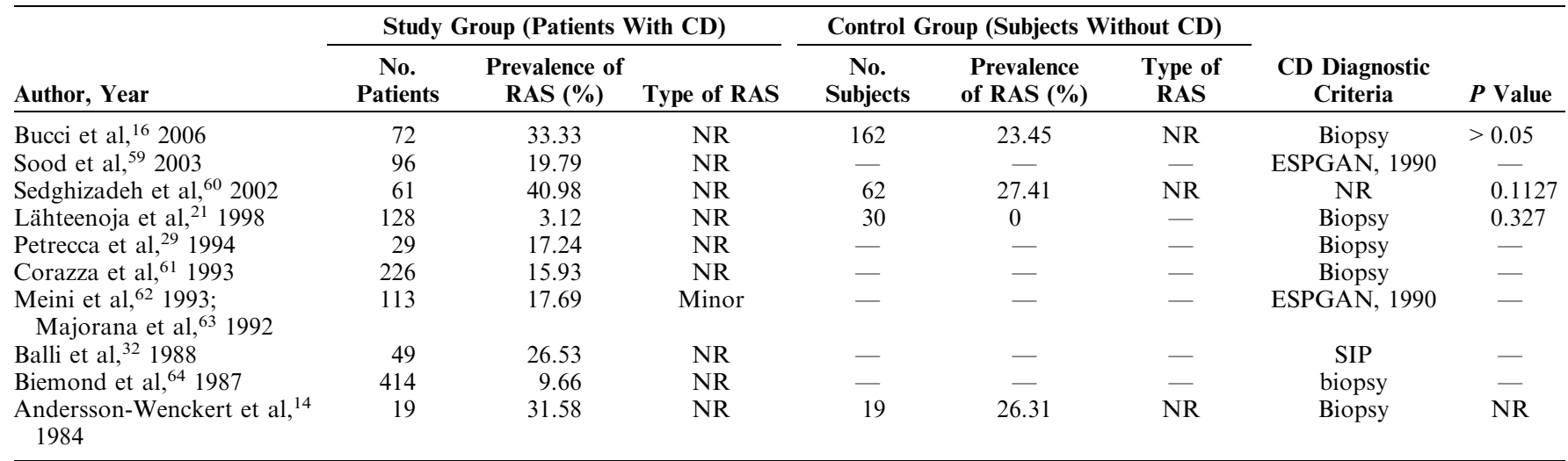

ESPGAN indicates European Society of Paediatric Gastroenterology and Nutrition (reference of the diagnostic criteria: Walker-Smith et al, ${ }^{35}$ 1990); NR, not reported; SIP, Società Italiana di Pediatria (Italian Society of Pediatrics; reference of the diagnostic criteria: Italian Society of Pediatrics, ${ }^{36}$ 1978).

130 patients with RAS were deficient in iron, vitamin $B_{12}$, or folic acid. ${ }^{57}$

Immuno-genetical factors could be also involved in this presumptive association, as the prevalence of HLA antigens DRw10 and DQw1 was demonstrated significantly higher in patients with $\mathrm{CD}$ and RAS than in patients with CD only. ${ }^{62,63}$ However, whether $\mathrm{CD}$ and $\mathrm{CD}$-associated aphthous ulcers are the consequence of a similar immunopathologic mechanism remains a matter of conjecture.

\section{Atrophic Glossitis}

A series of 128 patients with $C D$ and 30 healthy controls was examined for oral mucosal lesions and symptoms in a Finnish study. ${ }^{21}$ The tongue was most frequently affected, as $29.68 \%$ of CD patients referred soreness or burning sensation of the tongue (with a statistically significant difference as compared with control subjects) and $8.59 \%$ showed erythema or atrophy.

We can report the case of a man with erythema and atrophy on the dorsum of the tongue and without gastrointestinal complaints, whose serologic tests for $\mathrm{CD}$ were positive; the small-intestine biopsy confirmed the diagnosis of CD, and GFD resulted in resolution of the tongue lesion. ${ }^{69}$

We found no more paper that supports a correlation between $C D$ and glossitis. However, iron and vitamin $B_{12}$ deficiencies are frequent in untreated CD patients, ${ }^{68}$ and it is well known that such deficiencies may cause atrophic glossitis, often accompanied by soreness or burning sensation. ${ }^{70}$ Furthermore, several reports describe cases of $\mathrm{CD}$ associated with Plummer-Vinson syndrome. ${ }^{71-77}$ Plummer-Vinson syndrome (also referred as PatersonBrown Kelly syndrome, or sideropenic dysphagia) is a rare condition that comprises the classic triad of dysphagia, iron-deficiency anemia, and esophageal webs; other clinical features may also be observed, among these atrophic glossitis. $^{78}$

\section{Oral Lichen Planus}

Oral lichen planus (OLP) is a chronic inflammatory disorder affecting the oral mucosa with a spectrum of clinical conditions, including keratotic, atrophic, erosive, and ulcerative lesions. ${ }^{79}$

In 1993, an unusual association of OLP and CD was reported. ${ }^{80}$ This was the case of a 70 -year-old male with a biopsy-proven erosive OLP; iron, folate, and vitamin $\mathrm{B}_{12}$ deficiencies led to perform jejunal biopsy, that demonstrated CD. Surprisingly, GFD resulted in relief of OLP within 6 month. But the hypothesis of an association between CD and OLP was promptly refuted by Scully et $\mathrm{al}^{81}$ who 1 month later referred that they had investigated 103 patients with OLP and none had CD. So, they replied that OLP would seem only occasionally associated with CD.

In 1998, 39 consecutive patients with OLP were screened for $\mathrm{CD}$; 12 were positive for $\operatorname{IgA}$ gliadin antibody test and 2 for endomysium antibody test, but only 1 had small intestinal signs of CD. ${ }^{51}$ We found only another anecdotal report that describes OLP in a CD patient. ${ }^{82}$ Thus, there is currently insufficient evidence to support an association between CD and OLP.

\section{Oral Manifestations of DH}

DH is a pruritic bullous skin disease considered as a part of the spectrum of gluten-sensitive disorders. In fact, although patients with DH are unlikely to have gastrointestinal complaints, nearly all of them have some degree of small intestinal histopathologic changes identical to those of $\mathrm{CD}$, and they share the same serologic antibody profile of celiac subjects. ${ }^{83}$ Moreover, GFD is an effective therapy for DH, which confirms the role of an intestinal reaction to gluten in the pathogenesis of $\mathrm{DH} .{ }^{84}$ Typically, DH consists of symmetrical, erythematous, papulovesicular lesions that generally involve the extensor surfaces of the elbows, knees, buttocks, and scalp. Owing 
to their intense itching, lesions often look as skin erosions secondary to scratching.

In a study on 15 patients with $\mathrm{DH}$, oral lesions were found in 12 cases. ${ }^{85}$ Oral involvement consisted of erythematous, pseudo-vesicular, purpuric, and erosive lesions, but only in 2 cases the direct immunofluorescence examination revealed the typical granular deposits of $\operatorname{IgA}$ along the basement membrane, that is a sine qua non for the diagnosis of DH. Similarly, $57 \%$ of 27 patients with DH were found as having oral lesions, which included ulcerations, erythemas, and atrophies ${ }^{86}$; however, no direct immunofluorescence study was performed.

To the contrary, no oral mucosal involvement was described in a large review of 926 cases of $\mathrm{DH},{ }^{87}$ and only 1 case of small oral blisters was reported in a study on 149 DH patients. ${ }^{88}$ Rather, in an old paper ${ }^{89}$ the absence of oral lesions was referred as a diagnostic criterion for DH.

Actually, at present oral involvement in $\mathrm{DH}$ is considered very rare, and generally consists of vesicles and bullae that result in ulcers. ${ }^{90}$ Reports that describe DH lesions in the oral cavity are sparse ${ }^{91-95} ; 2$ of these $^{91,95}$ relate cases of oral manifestations appeared before the onset of the skin lesions.

\section{Other Oral Soft Tissue Lesions}

Oral mucosal malignancies were described in celiac patients; these include carcinoma of the tongue $72,96,97$ and oral T-cell lymphoma. ${ }^{98}$ Occurrence of T-cell lymphoma in the oral cavity is uncommon for celiac patients, as CDrelated lymphomas usually develop in the upper small intestine. In addition, 8 cancers of oral cavity and pharynx were detected out of $11,019 \mathrm{CD}$ subjects. ${ }^{99}$

A case of oral mucosal melanosis was observed in a 32-year-old celiac woman, also affected by neuropathies and unspecified "dental irregularities"100; GFD resulted in improvement of neurologic findings, but not of oral hyperpigmentation.

An occasional association of $\mathrm{CD}$ and cicatricial pemphigoid with involvement of tongue, buccal mucosa, gingiva, and floor of mouth has been recently reported in a 14 -year-old girl. ${ }^{101}$

\section{DISCUSSION}

Contrary to early beliefs, CD is a relatively common disease, with a mortality rate higher than that of the general population, mainly owing to long-term complications (eg, autoimmune diseases, malignancies). Diagnosis of $\mathrm{CD}$ is relatively easy in cases with typical signs and symptoms (ie, chronic diarrhea, abdominal pain and distention, weight loss). However, the majority of patients suffers from atypical or silent forms, for which diagnosis is often difficult. As a consequence, although its estimated prevalence is nowadays significantly higher than previously thought, it is reasonable to presume that $\mathrm{CD}$ still remains underdiagnosed. ${ }^{102}$

CD fulfils the WHO criteria for mass screenings. ${ }^{103}$ In fact, it is a common disorder with a significant morbidity and an effective treatment; its early detection could be difficult on a clinical basis; if not diagnosed, it could result in severe complications difficult to manage. Moreover, although the small intestinal biopsy remains the gold standard for the diagnosis of $\mathrm{CD}$, current diagnostic serologic tests (mostly endomysium antibodies and tissue transglutaminase antibodies) have optimal specificity and sensitivity approaching $100 \% .{ }^{104}$ Thus, they are suitable as screening tests. However, at present there is insufficient evidence to recommend mass screening for $\mathrm{CD}$, while case-finding in high-risk groups (ie, subjects with clinical conditions well-known to be associated with CD) seems effective, and currently represents the best epidemiologic approach to detect atypical cases. ${ }^{105}$ First-degree relatives of celiac individuals and subjects with type I diabetes, autoimmune thyroid disease, unexplained osteoporosis, unexplained abnormal liver biochemistry, irritable bowel syndrome, and unexplained infertility or miscarriage are considered at-risk groups ${ }^{105}$; for them serologic CD testing should be considered.

A few oral ailments have been described in celiac patients. Among these, systematic DEDs are those with the strongest evidence of a correlation with $\mathrm{CD}$, and should be counted in the extraintestinal manifestations of the disease. Subjects with systematic DEDs should be considered at-risk for $\mathrm{CD}$, and thus they should undergo serologic screening tests for gluten intolerance.

As regards aphthous ulcers, although an association with CD should seem plausible. Currently, we lack robust evidence-based data to recommend CD screening tests for subjects with recurrent aphthae. However, hematologic investigations (such as full blood cell count and measurement of serum iron, ferritin, vitamin $\mathrm{B}_{12}$, and folic acid) are often included in the standard diagnostic protocols for RAS, ${ }^{43}$ albeit elements in support of routine hematologic testing in patients with aphthae are lacking. ${ }^{45}$ At any rate, a suspicion of CD should arise in cases of RAS associated with hematinic deficiencies. Similarly, $\mathrm{CD}$ testing could be considered in those patients with idiopathic atrophic glossitis for which hematologic investigations reveal an underlying haematinic deficiency.

In summary, oral cavity may be involved in $\mathrm{CD}$. DEDs are the oral lesions most closely related to CD; patients with systematic enamel defects have to be recognized as at-risk subjects, and they should undergo screening tests even in the absence of gastrointestinal symptoms. On the other hand, there is insufficient evidence to recommend routine $\mathrm{CD}$ screening tests for patients with RAS, and also for subjects with idiopathic atrophic glossitis. Nevertheless, we would alert physicians and dental practitioners to consider $\mathrm{CD}$ in managing these patients, especially if clinical conditions that could be the result of CD are present.

\section{REFERENCES}

1. Rostom A, Murray JA, Kagnoff MF. American Gastroenterological Association (AGA) Institute technical review on the diagnosis and management of celiac disease. Gastroenterology. 2006;131: 1981-2002.

2. Dewar DH, Ciclitira PJ. Clinical features and diagnosis of celiac disease. Gastroenterology. 2005;128(4 suppl):19S-24S. 
3. Brousse N, Meijer JW. Malignant complications of coeliac disease. Best Pract Res Clin Gastroenterol. 2005;19:401-412.

4. Peters U, Askling J, Gridley G, et al. Causes of death in patients with celiac disease in a population-based Swedish cohort. Arch Intern Med. 2003;163:1566-1572.

5. Corrao G, Corazza GR, Bagnardi V, et al. Mortality in patients with coeliac disease and their relatives: a cohort study. Lancet. 2001;358:356-361.

6. Green PH, Jabri B. Coeliac disease. Lancet. 2003;362:383-391.

7. Elcock C, Lath DL, Luty JD, et al. The new Enamel Defects Index: testing and expansion. Eur J Oral Sci. 2006;114(suppl 1):35-38.

8. Black GV. Operative Dentistry: The Pathology of Hard Tissues of the Teeth. Chicago: Medico-Dental Publishing Co; 1908.

9. Hertz M. Follow-up in cases of celiac disease. Ugeskr Laeger. 1955;117:477-481 [in Danish].

10. Smith DM, Miller J. Gastro-enteritis, coeliac disease and enamel hypoplasia. Br Dent J. 1979;147:91-95.

11. Rasmussen P, Espelid I. Coeliac disease and dental malformation. ASDC J Dent Child. 1980;47:190-192.

12. Romankiewicz-Wozniczko G, Erecinska K, Kaczmarczyk J. The state of the oral cavity in children following celiac disease. Wiad Lek. 1973;26:1011-1017 [in Polish].

13. Shmerling DH, Sacher M, Widmer B, et al. Incidence of dental caries in coeliac children. Arch Dis Child. 1980;55:80-81.

14. Andersson-Wenckert I, Blomquist HK, Fredrikzon B. Oral health in coeliac disease and cow's milk protein intolerance. Swed Dent J. 1984;8:9-14.

15. Aine L. Dental enamel defects and dental maturity in children and adolescents with coeliac disease. Proc Finn Dent Soc. 1986; 82(suppl 3): 1-71.

16. Bucci P, Carile F, Sangianantoni A, et al. Oral aphthous ulcers and dental enamel defects in children with coeliac disease. Acta Paediatr. 2006;95:203-207.

17. Farmakis E, Puntis JW, Toumba KJ. Enamel defects in children with coeliac disease. Eur J Paediatr Dent. 2005;6:129-132.

18. Ciacci C, Iovino P, Amoruso D, et al. Grown-up coeliac children: the effects of only a few years on a gluten-free diet in childhood. Aliment Pharmacol Ther. 2005;21:421-429.

19. Priovolou $\mathrm{CH}$, Vanderas AP, Papagiannoulis L. A comparative study on the prevalence of enamel defects and dental caries in children and adolescents with and without coeliac disease. Eur J Paediatr Dent. 2004;5:102-106.

20. Rasmusson CG, Eriksson MA. Celiac disease and mineralisation disturbances of permanent teeth. Int J Paediatr Dent. 2001;11: $179-183$.

21. Lähteenoja H, Toivanen A, Viander $\mathbf{M}$, et al. Oral mucosal changes in coeliac patients on a gluten-free diet. Eur J Oral Sci. 1998;106:899-906.

22. Aguirre JM, Rodriguez R, Oribe D, et al. Dental enamel defects in celiac patients. Oral Surg Oral Med Oral Pathol Oral Radiol Endod. 1997;84:646-650.

23. Rea F, Serpico R, Pluvio R, et al. Dental enamel hypoplasia in a group of celiac disease patients. Clinico-epidemiologic correlations. Minerva Stomatol. 1997;46:517-524 [in Italian].

24. Ventura A, Martelossi S. Dental enamel defects and coeliac disease. Arch Dis Child. 1997;77:91.

25. Martelossi S, Torre G, Zanatta M, et al. Dental enamel defects and screening for coeliac disease. Pediatr Med Chir. 1996;18:579-581.

26. Bertoldi C, Balli F, Tanza D, et al. Experimentation and clinical analysis of the interrelationships between dental damage and celiac disease. Minerva Stomatol. 1995;44:95-105 [in Italian].

27. Mariani P, Mazzilli MC, Margutti G, et al. Coeliac disease, enamel defects and HLA typing. Acta Paediatr. 1994;83:1272-1275.

28. Ballinger A, Hughes C, Kumar P, et al. Dental enamel defects in coeliac disease. Lancet. 1994;343:230-231.

29. Petrecca S, Giammaria G, Giammaria AF. Oral cavity changes in the child with celiac disease. Minerva Stomatol. 1994;43:137-140 [in Italian].

30. Aine L, Maki M, Reunala T. Coeliac-type dental enamel defects in patients with dermatitis herpetiformis. Acta Derm Venereol. 1992;72:25-27.
31. Aine L, Maki M, Collin P, et al. Dental enamel defects in celiac disease. J Oral Pathol Med. 1990;19:241-245.

32. Balli MP, Balli ME, Mengoli M, et al. Growth, skeletal and dental age in chronic diarrhea in childhood. Pediatr Med Chir. 1988;10: 277-282 [in Italian].

33. Prati C, Santopadre A, Baroni C. Delayed eruption, enamel hypoplasia and caries in childhood celiac disease. Minerva Stomatol. 1987;36:749-752 [in Italian].

34. Meeuwisse GW. Diagnostic criteria in coeliac disease. Acta Paediatr Scand. 1970;59:461-463.

35. Walker-Smith JA, Guandalini S, Schmitz J, et al. Revised criteria for diagnosis of coeliac disease. Report of working group of European Society of Paediatric Gastroenterology and Nutrition. Arch Dis Child. 1990;65:909-911.

36. Italian Society of Pediatrics. Protocol for the diagnosis of celiac disease. Rivista Italiana di Pediatria. 1978;4:287 [in Italian].

37. Nikiforuk G, Fraser D. The etiology of enamel hypoplasia: a unifying concept. J Pediatr. 1981;98:888-893.

38. Maki M, Aine L, Lipsanen V, et al. Dental enamel defects in firstdegree relatives of coeliac disease patients. Lancet. 1991;337: 763-764.

39. Aine L. Permanent tooth dental enamel defects leading to the diagnosis of coeliac disease. Br Dent J. 1994;177:253-254.

40. McLoughlin MJ, McNeill S, Egan-Mitchell B, et al. Incidence of dental caries in coeliac children. Arch Dis Child. 1980;55:80.

41. Schour I, Massler M. The development of the human dentition. J Am Dental Assoc. 1941;28:1153-1160.

42. Marzec-Koronczewska Z. The condition of the stomatognathic system in children with gluten-dependent coeliac disease. Czas Stomatol. 1990;43:207-212 [in Polish].

43. Jurge S, Kuffer R, Scully C, et al. Mucosal disease series. Number VI. Recurrent aphthous stomatitis. Oral Dis. 2006;12:1-21.

44. Natah SS, Konttinen YT, Enattah NS, et al. Recurrent aphthous ulcers today: a review of the growing knowledge. Int $J$ Oral Maxillofac Surg. 2004;33:221-234.

45. Scully C. Clinical practice. Aphthous ulceration. $N$ Engl J Med. 2006:355:165-172.

46. Ferguson R, Basu MK, Asquith P, et al. Jejunal mucosal abnormalities in patients with recurrent aphthous ulceration. Br Med J. 1976;1:11-13.

47. Olszewska M, Sulej J, Kotowski B. Frequency and prognostic value of $\operatorname{IgA}$ and $\mathrm{IgG}$ endomysial antibodies in recurrent aphthous stomatitis. Acta Derm Venereol. 2006;86:332-334.

48. Aydemir S, Tekin NS, Aktunc E, et al. Celiac disease in patients having recurrent aphthous stomatitis. Turk J Gastroenterol. 2004; 15:192-195.

49. Robinson NA, Porter SR. Low frequency of anti-endomysial antibodies in recurrent aphthous stomatitis. Ann Acad Med Singapore. 2004;33:43-47.

50. Nowak M, Dziechciarz P, Dwilewicz-Trojaczek J. The frequency of coeliac disease occurrence in patients with recurrent aphthous stomatitis (RAS)-preliminary report. Wiad Lek. 2002;55:542-546 [in Polish].

51. Jokinen J, Peters U, Maki M, et al. Celiac sprue in patients with chronic oral mucosal symptoms. J Clin Gastroenterol. 1998;26: 23-26.

52. Tavarela Veloso F, Vaz Saleiro J. Small-bowel changes in recurrent ulceration of the mouth. Hepatogastroenterology. 1987; 34:36-37.

53. Merchant NE, Ferguson MM, Ali A, et al. The detection of IgAreticulin antibodies and their incidence in patients with recurrent aphthae. J Oral Med. 1986;41:31-34.

54. Tyldesley WR. Recurrent oral ulceration and coeliac disease. A review. Br Dent J. 1981;151:81-83.

55. Ferguson MM, Wray D, Carmichael HA, et al. Coeliac disease associated with recurrent aphthae. Gut. 1980;21:223-226.

56. Rose JD, Smith DM, Allan FG, et al. Recurrent aphthous ulceration and jejunal biopsy. $\mathrm{Br}$ Med J. 1978;1:1145.

57. Wray D, Ferguson MM, Mason DK, et al. Recurrent aphthae: treatment with vitamin B12, folic acid, and iron. $\mathrm{Br}$ Med $\mathrm{J}$. $1975 ; 2: 490-493$. 
58. Ferguson R, Basu MJ, Asquith P, et al. Proceedings: recurrent aphthous ulceration and its association with coeliac disease. Gut. 1975; 16:393.

59. Sood A, Midha V, Sood N, et al. Adult celiac disease in northern India. Indian J Gastroenterol. 2003;22:124-126.

60. Sedghizadeh PP, Shuler CF, Allen CM, et al. Celiac disease and recurrent aphthous stomatitis: a report and review of the literature. Oral Surg Oral Med Oral Pathol Oral Radiol Endod. 2002;94: 474-478.

61. Corazza GR, Frisoni M, Treggiari EA, et al. Subclinical celiac sprue. Increasing occurrence and clues to its diagnosis. $J$ Clin Gastroenterol. 1993;16:16-21.

62. Meini A, Pillan MN, Plebani A, et al. High prevalence of DRW10 and DQW1 antigens in celiac disease associated with recurrent aphthous stomatitis. Am J Gastroenterol. 1993;88:972.

63. Majorana A, Sapelli PL, Malagoli A, et al. Celiac disease and recurrent aphthous stomatitis. The clinical and immunogenetic aspects. Minerva Stomatol. 1992;41:33-40 [in Italian].

64. Biemond I, Pena AS, Groenland F, et al. Coeliac disease in The Netherlands: demographic data of a patient survey among the members of the Dutch Coeliac Society. Neth J Med. 1987;31: 263-268.

65. Biel K, Bohm M, Luger TA, et al. Long-standing oral aphthae-a clue to the diagnosis of coeliac disease. Dermatology. 2000;200:340.

66. Wray D. Gluten-sensitive recurrent aphthous stomatitis. Dig Dis Sci. 1981;26:737-740.

67. Hunter IP, Ferguson MM, Scully C, et al. Effects of dietary gluten elimination in patients with recurrent minor aphthous stomatitis and no detectable gluten enteropathy. Oral Surg Oral Med Oral Pathol. 1993;75:595-598.

68. Ciclitira PJ, Johnson MW, Dewar DH, et al. The pathogenesis of coeliac disease. Mol Aspects Med. 2005;26:421-458.

69. Pastore L, Lo Muzio L, Serpico R. Atrophic glossitis leading to the diagnosis of celiac disease. $N$ Engl J Med. 2007;356:2547.

70. Neville BW, Damm DD, Allen CM, et al. Oral and Maxillofacial Pathology. 2nd ed. Philadelphia: Saunders; 2002.

71. Dickey W, McConnell B. Celiac disease presenting as the PatersonBrown Kelly (Plummer-Vinson) syndrome. Am J Gastroenterol. 1999; $94: 527-529$

72. Jessner W, Vogelsang H, Puspok A, et al. Plummer-Vinson syndrome associated with celiac disease and complicated by postcricoid carcinoma and carcinoma of the tongue. $\mathrm{Am}$ J Gastroenterol. 2003;98:1208-1209.

73. Makharia GK, Nandi B, Garg PK, et al. Plummer Vinson syndrome: unusual features. Indian J Gastroenterol. 2002;21:74-75.

74. Malhotra P, Kochhar R, Varma N, et al. Paterson-Kelly syndrome and celiac disease - a rare combination. Indian $J$ Gastroenterol. 2000;19:191-192.

75. Rashid Z, Kumar A, Komar M. Plummer-Vinson syndrome and postcricoid carcinoma: late complications of unrecognized celiac disease. Am J Gastroenterol. 1999;94:1991.

76. River GL, Aronson AR. Plummer-Vinson syndrome with celiac sprue. Wis Med J. 1965;64:391-395.

77. Sood A, Midha V, Sood N, et al. Paterson Kelly syndrome in celiac disease. J Assoc Physicians India. 2005;53:991-992.

78. Novacek G. Plummer-Vinson syndrome. Orphanet $J$ Rare Dis. 2006;1:36.

79. Lodi G, Scully C, Carrozzo M, et al. Current controversies in oral lichen planus: report of an international consensus meeting. Part 1. Viral infections and etiopathogenesis. Oral Surg Oral Med Oral Pathol Oral Radiol Endod. 2005;100:40-51.

80. Fortune F, Buchanan JA. Oral lichen planus and coeliac disease. Lancet. 1993;341:1154-1155.

81. Scully C, Porter SR, Eveson JW. Oral lichen planus and coeliac disease. Lancet. 1993;341:1660.

82. Ruiz Villaverde R, Blasco Melguizo J, Menendez Garcia Estrada A, et al. Erosive mucosal lichen associated to hyper IgE syndrome and coeliac disease. An Pediatr (Barc). 2004;60:281-282 [in Spanish].

83. Nicolas ME, Krause PK, Gibson LE, et al. Dermatitis herpetiformis. Int J Dermatol. 2003;42:588-600.

84. Oxentenko AS, Murray JA. Celiac disease and dermatitis herpetiformis: the spectrum of gluten-sensitive enteropathy. Int J Dermatol. 2003;42:585-587.

85. Fraser NG, Kerr NW, Donald D. Oral lesions in dermatitis herpetiformis. Br J Dermatol. 1973;89:439-450.

86. Lahteenoja $\mathrm{H}$, Irjala $\mathrm{K}$, Viander $\mathrm{M}$, et al. Oral mucosa is frequently affected in patients with dermatitis herpetiformis. Arch Dermatol. 1998:134:756-758.

87. Lodin A, Stigell PO. Dermatitis herpetiformis. Cases observed at the Dermatologic Clinic, Karolinska Sjukhuset, 1954-1963. Acta Derm Venereol. 1965;45:355-365.

88. Smith EL. The diagnosis of dermatitis herpetiformis. Trans St Johns Hosp Dermatol Soc. 1966;52:176-196.

89. Tolman MM, Moschella SL, Schneiderman RN. Dermatitis herpetiformis; specific entity or clinical complex. $J$ Invest Dermatol. 1959;32:557-561

90. Regezi JA, Sciubba JJ, Jordan RCK. Oral Pathology-Clinical Pathological Correlations. 4th ed. St Louis: Saunders; 2003.

91. Economopoulou P, Laskaris G. Dermatitis herpetiformis: oral lesions as an early manifestation. Oral Surg Oral Med Oral Pathol. 1986;62:77-80

92. Gasimov FG, Khamidullina SA, Khitrov V. Isolated oral mucosal lesions in Duhring's disease. Stomatologiia (Mosk). 1980;59:18-19 [in Russian]

93. Krunic R, Ljubic V. Dermatitis herpetiformis of Duhring-Broco manifested in the mouth mucosa. Stomatol Vjesn. 1967;1:253-257 [in Croatian].

94. Rantala I, Hietanen J, Soidinmaki H, et al. Immunoelectron microscopic findings in oral mucosa of patients with dermatitis herpetiformis and linear IgA disease. Scand J Dent Res. 1985;93: 243-248.

95. Schimpf A. Dermatitis herpetiformis (Duhring), with intermittent isolated involvement of the mucosa. Arch Klin Exp Dermatol. 1964;220:250-260 [in German].

96. Card TR, West J, Holmes GK. Risk of malignancy in diagnosed coeliac disease: a 24-year prospective, population-based, cohort study. Aliment Pharmacol Ther. 2004;20:769-775.

97. Holmes GK. Coeliac disease and malignancy. Dig Liver Dis. 2002:34:229-237.

98. Shiboski CH, Greenspan D, Dodd CL, et al. Oral T-cell lymphoma associated with celiac sprue. A case report. Oral Surg Oral Med Oral Pathol. 1993;76:54-58

99. Askling $\mathbf{J}$, Linet $\mathbf{M}$, Gridley $\mathrm{G}$, et al. Cancer incidence in a population-based cohort of individuals hospitalized with celiac disease or dermatitis herpetiformis. Gastroenterology. 2002;123: $1428-1435$

100. Somay G, Cevik DM, Halac GU, et al. Cobalamine deficiency associated with neuropathy and oral mucosal melanosis in untreated gluten-sensitive enteropathy. Indian $J$ Gastroenterol. $2005 ; 24: 120-122$

101. Kanwar AJ, Ajith C, Narang T. Cicatricial pemphigoid associated with coeliac disease in a child. J Eur Acad Dermatol Venereol. 2006;20:1148-1150.

102. Mearin ML, Ivarsson A, Dickey W. Coeliac disease: is it time for mass screening? Best Pract Res Clin Gastroenterol. 2005;19: 441-452.

103. Fasano A. European and North American populations should be screened for coeliac disease. Gut. 2003;52:168-169.

104. Rostom A, Dube C, Cranney A, et al. The diagnostic accuracy of serologic tests for celiac disease: a systematic review. Gastroentero$\log y$. 2005;128(4 suppl):38S-46S.

105. Mulder CJ, Bartelsman JF. Case-finding in coeliac disease should be intensified. Best Pract Res Clin Gastroenterol. 2005;19:479-486. 